\title{
Making Use of Operations Research Techniques in Nigerian Business Organizations
}

\author{
Ighomereho, O. Salome \\ (Department of Economics and Business Studies, Redeemer's University, Ogun State, Nigeria)
}

\begin{abstract}
Operations Research is a problem solving and decision-making science. It is a kit of scientific and programmable rules that provide managers at all levels with a quantitative basis for decision-making. However, research has indicated that majority of managers in Nigerian business organizations do not make use of operations research techniques. The principles and concepts of Operations Research could be very helpful in a dynamic, competitive and complex business environment like the Nigerian business environment. In order to provide an understanding of the role of Operations Research in business decision making, this paper examines the nature of Operations Research, the Operations Research techniques available for managers and the various areas of operation where they can be applied. Finally, recommendations as to how its use could be enhanced are proposed.
\end{abstract}

Keywords: Operations Research, decision-making, business organizations, managers, problem solving

\section{Introduction}

Organizations are set up to achieve goals and objectives. In trying to achieve the goals and objectives, decisions are to be made and resources have to be deployed. One of the techniques that can assist managers of business organizations in this regard is Operations Research. It assists managers in making effective decisions in order to achieve efficiency, increase productivity and overall corporate performance (INFORMS, 2005). According to Akingbade et al (1991) it is a problem-solving science-based activity using analysis and modelling as a basis for aiding decision-makers in organizations to improve the performance of the operations under their control. It is concerned with analyzing complex problems and assisting decision-makers work out the best means of achieving objectives. It can be said to have been in existence since the beginning of mankind (Agbadudu, 2006). However, the concept emerged in 1940 during world war 1l, when a team of scientist was called upon by the military management in England to develop ways to make the most effective use of limited military resources (Anderson et al, 1997 and Taha, 2002). Their mission was to formulate specific proposals and plans for aiding the military commands to arrive at decisions on optimal utilization of scarce military resources and also to implement the decisions effectively. The name "Operations Research" originated because the team was handling research on (military) operations. The United States military management took a leaf from the British military management and started the use of Operations Research.

Due to the successful utilization of Operations Research by military management in Britain and United States, managers of business organizations became interested in using the techniques to solve organizational problems. Consequently, in the early 1950's, business organizations began to absorb some of the Operations Research men who trickled out of the military (Ekoko, 1999). Today, Operations Research is a dominant and indispensable decision making tool and is widely used in business organizations in western countries. This led to the formation of professional bodies such as Operational Research Society of America (ORSA), American Institute of Decision Sciences (AIDS), European Operational Research Society (EURO), The Institute of Management Sciences (TIMS) now known as Institute For Operations Research and Management Sciences (INFORMS) and International Federation of Operational Research Societies (IFORS) which is an organization made up of national Operations Research Societies all over the world.

Despite the fact that Operations Research has been a compulsory course for all business students in Nigerian universities and there is a professional body, the Institute For Operations Research of Nigeria (INFORN) Foster (1986), Akingbade et al (1991), (Agbadudu, 1996; 2006) and Ighomereho (2007) have noted that the use of Operations Research in Nigerian business organizations is still limited because not much of it is practiced at the moment. The objectives of this paper therefore are to examine the nature of Operations Research, the development of Operations Research, the steps in Operations Research, the various Operations Research techniques available for managers of Nigerian business organizations and the areas of operation where they can be applied.

\section{The Concept and Nature of Operations Research}

Operations Research has been defined in various ways by different authors. Right from its formal inception in 1940, there has not been a consensus about its definition. The reason usually given is that it is too 
broad in scope for such a consensus. Churchman and Arnoff (1957) defined Operations Research as a systematic study of the basic structures, characteristics, functions and relationships of an organization to provide executives with a sound, scientific and quantitative basis for decision making. Saaty (1961) in his opinion defined it as the art of giving bad answers to problems to which otherwise worse answer are given. In another view, Ekoko (1999) defined it as the application of scientific method by interdisciplinary teams to problems involving the control of organized systems so as to provide solutions which best serve the purpose of the organization as a whole while Lucey (2002) defined it as the attack of modern science on complex problems arising in the direction and management of large systems of men, machines, materials and money in industry, business, government and defence. For the purpose of this paper, the definition by Kalavathy (2002) will be adopted. He defined Operations Research as the application of quantitative techniques to aid and improve management's decision making. Indeed, Operations Research is a scientific approach for analyzing problems and making decisions in organizations. It aims at providing rational bases for decision making by seeking to understand and structure complex situations and to use this understanding to predict system behaviour and improve performance. The distinctive approach is to develop a scientific model of the system incorporating measurements of factors such as change and risk with which to predict and compare the outcomes of alternative decisions and strategies. The purpose is to help management determine its policy and actions scientifically.

\section{Development of Operations Research}

Over the years, Operations Research has evolved through different stages. Magee (1973) reviewed the phases through which it has developed. According to him, it has gone through three phases of growth; the primitive phase, the academic phase and the maturing phase. In this paper, the matured phase is included.

\section{The Primitive Phase}

This phase is between 1940 and 1960. At this stage, the problem solvers were interested in practical operational problems. These problems were well defined and capable of being handled by the smaller, less sophisticated computers available then. Also, it was in the process of developing into a separate professional field and the theoretical foundations of the discipline developed rapidly. However, only very few Universities offered formal training in Operations Research.

\section{The Academic Phase}

In the early 1960s, the number of Universities offering programmes in Operations Research grew over 500 percent. Magee pointed out that in this phase, people with some Operations Research experience began to be found at the higher corporate levels in private enterprises. The increasing speed and availability of computers were of great help during this time. Magee noted that research during this phase tended to be academic, that is, it was more concerned with developing theory than with finding workable applications. Also, it was during this time that the limitations of Operations Research became evident.

\section{Maturing Phase}

Magee described the maturing phase as a time when balance between theory and practice was obtained. He argued that even though evidence of such concerns was noted years ago, the real thrust towards practice and applications did not come until the 1970s. Magee's ideas about the maturing phase include:

- More realistic understanding by managers of what Operations Research can and cannot accomplish

- More attention paid to getting the facts compared with development of abstract techniques.

- Less attention to finding optimum answers but more to developing processes and evolving successively better answers adapted to evolving circumstances.

- Better integration of behavioural, functional and quantitative analysis.

\section{The Matured Phase}

This is the $21^{\text {st }}$ century phase of Operations Research. In this phase, it has become a compulsory course for undergraduate students especially those in management sciences and engineering. It is also offered as a course of study at the Masters and Ph. D levels in most universities. This phase has also featured the use of software packages that have removed the burden of computation

\section{The Importance and Limitations of Operations Research}

Decisions, especially business decisions, can be characterized by many interrelated factors. The combined impact of the interrelated factors is rarely obvious, so that intuition and common sense alone do not necessarily lead to good decision-making. This is not to suggest that common sense, intuition, executive 
judgement and experience are irrelevant in decision-making but purely subjective decision-making might not be sufficient (Anderson et al, 1997). If the manager has had experience with similar problems or if the problem is relatively simple, heavy emphasis may be placed on qualitative analysis. It is an undeniable fact that we are living in a changing world. As old problems are solved, new problems arise with new structures and relations and this has effect on decision-making. As a result, managers need help and Operations Research techniques have the potential capability to support this need (INFORMS, 2005). A quantitative analysis is important when:

- The problem is complex and the manager cannot develop a good solution without the aid of quantitative analysis. When management is faced with more decision factors than they feel they can cope with, Operations Research can be used to analyze complex real-world systems with the goal of improving or optimizing performance.

- The problem is very important. For example, a great deal of money is involved and the manager desires a thorough analysis before attempting to make a decision.

- The problem is new and the manager has no previous experience from which to draw. When managers face great uncertainty about the operating environment and what could happen as a consequence of various decisions, Operations Research techniques can model various scenarios, undertake 'what-if' analysis and help to determine potential outcomes and strategies.

- Management is troubled by risk. Assessing the risk of a new project or contract can be tricky. Operations Research can help to quantify risk, which is a key to controlling it and help to plan how best to balance risk against the gains an organization can expect.

- The organization is not making the most of its data. Most organizations probably track information about many aspects of their operations and have huge amounts of data they do not use for decision-making. Operations Research specializes in working with data, extracting the most valuable information from what is currently collected and indicating the additional data that could be collected to increase the value even further.

Agbadudu (1996) stated two reasons for using Operations Research to solve real world problems. They are:

- It is more difficult to cheat conclusion with mathematical argument. The results of a mathematical debate are precise and depend only on the initial assumptions. For a given set of assumptions, the mathematical conclusions are accurately expressed and their results cannot be argued.

- With a mathematical description, it is possible to arrive at optimal solutions, which would not be obvious without analysis.

Despite the relevance of Operations Research to organizations, Griffen (1987) argued that quantitative techniques cannot fully account for intangible or qualitative factors in decision-making. Qualitative or intangible factors are factors that are difficult to measure numerically. For example, individual behaviour and attitudes, employee morale, image of the organization are major factors in managerial decisions but they cannot be quantified. Another weakness of quantitative aids is that they may not always adequately reflect reality. Mathematical models may require a set of assumptions that may not be realistic. In addition, for most techniques, the manager must identify and characterize all variables to be considered. When the solution is subsequently implemented, a variable that has gone unaccounted for may influence it in some way. According to Agbadudu (1996) the limitations of Operations Research are:

- Much time and effort can be wasted in finding solutions for rather irrelevant problems that are so far remote from reality and their solutions have little meaning to the prevailing problem.

- At times, a manager's practical experience and initiation would be a better judgement than unnecessary vigorous mathematical analysis.

- Costly in both time and resources.

As a result of these limitations, when using Operations Research, the decision maker should concentrate on the quantitative facts or data associated with the problem and develop mathematical expressions that describe the objectives, constraints and other relationships that exist in the problem. He/she can then combine the two sources (quantitative and qualitative) in order to make the best possible decision. It should be noted that Operations Research may be useful in some situations but not in others that may call for a more intuitive approach. Although the best decisions are based on sound information (Nickels et al, 2002), managers deciding rationally must have a clear understanding of the alternative courses by which a goal can be achieved under existing circumstances and limitations. They must also have the information and the ability to analyze and evaluate alternatives and also be eager to choose the best solution by selecting the alternative that most effectively satisfies goal achievement (Weihrich and Koontz, 2005). However, due to the limitations of 
information, time and certainty, the satisficing or limited or Bounded Rationality introduced by Simon (1997) is usually advocated. This involves choosing a course of action that is satisfactory or good enough under the circumstances. Operations Research does not result in decisions, but it generates enough quantified data to direct the decision maker to the most plausible decision. This suggests that common sense, intuition, executive judgement and experience are also relevant in decision-making but purely subjective decision-making might not be sufficient.

\section{The Steps in Operations Research}

Operations Research encompasses a logical and systematic approach to problem solving. This approach follows a generally recognized and ordered set of steps as shown in the figure below:

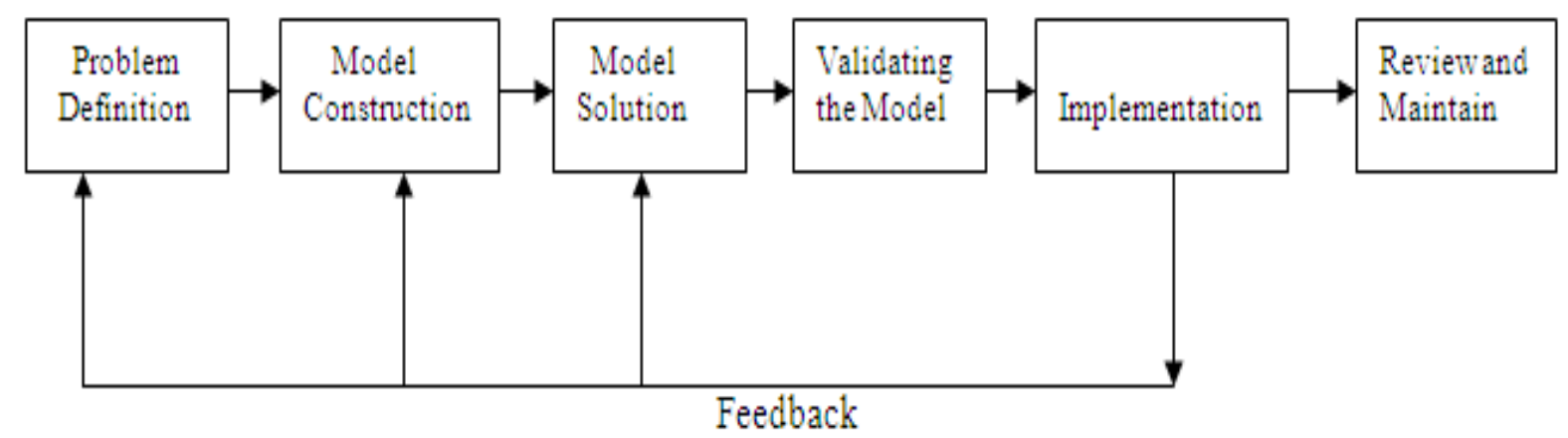

\section{Source: Adapted from Taylor and Bernard (1996:2)}

\section{Problem Definition}

The first step in Operations Research approach is to define the organization's problem. Problems are not always the result of a crisis that must be reacted to, they can also be anticipated. Once it has been determined that a problem exists, the problem must be clearly and concisely defined. In many cases, defining the problem is the most important and the most difficult step. It is important to go beyond the symptoms of the problem and identify the true causes. One problem may be related to other problems, solving one problem without regard to other related problems can make the entire situation worse. It is important to analyze how the solution to one problem affects other problems or the situation in general. Defining the problem also involves specifying the organization's objectives. In the view of Ekoko (1999) the existence of a problem implies that the objectives of the firm are not being met and so the objectives of the organization must be clearly defined. A stated objective helps to focus attention on what the problem actually is.

\section{Model Construction}

After formulating the problem, the next step is to develop a model that attempts to capture the essential features of the problem under consideration. Taylor and Bernard (1996) defined a model as a simplified representation of an existing problem situation. Operations Research models usually consist of mental models, verbal models, diagrams and mathematical models (Akingbade et al, 1991). However, the most widely used Operations Research models are the mathematical models which comprise a set of mathematical relationships. The objective of a model is to identify significant factors and interrelationships. The reliability of the solution obtained from a model depends on the validity of the model representing the real system. In discussing model formulation, Wayne (1994) suggested that models should be developed carefully. They should be solvable, realistic, easy to understand and modify and the required input data should be obtainable and that in complex situations were analytic models cannot be formulated, the analysts should develop a simulation model, which enables a computer to approximate the behaviour of the actual system. This phase also involves the collection of data to estimate the values of parameters that affect the organization's problem. These estimates are used to develop the model. According to Barry and Stair (1997) obtaining accurate data for the model is essential because even if the model is a perfect representation of reality, improper data will result in misleading results.

\section{Model Solution}

Developing a solution involves manipulating the model to arrive at the best (optimal) solution to the problem. In some cases, this requires that an equation be solved for the best decision. In other cases, a trial and error method is used, trying various approaches and picking the one that result in the best decision. The accuracy of the solution depends on the accuracy of the input data and the model. 
Levin et al (1992) stated that Operations Research solutions which really work ought to meet these requirements:

- The solution should be technically appropriate. It should produce a solution which works technically, which meets the constraints and which operates in the problem environment.

- The solution should be reliable. It should work consistently under the conditions for which it was designed.

- The solution should be economically viable. It should produce value for the organization in excess of what it costs.

- The solution should be behaviourally appropriate. It should be viable in its organizational setting and it should have the support of management.

It will also be necessary to carry out sensitivity analysis of the optimal solution for some changes in the uncontrollable variables. These analyses are necessary because some of the variables change overtime. For example, the prices of raw materials fluctuate, cheaper when in season and costly when out of season.

\section{Validating the Model}

Model validation concerns the efforts that are made to demonstrate that the model and the solution are sufficiently realistic to serve as a solid foundation for subsequent management action. The validation process includes careful consideration of assumptions, a review of data that were used in the model and checks to detect mathematical or arithmetic errors. To determine how well the model fits reality, one determines how valid the model is for the current situation. Ekoko (1999) defined a validated model as one that has been proven to be reasonable abstraction of the real problem it is intended to represent. The usual approach to validation consists of comparing the model's performance with the performance of the actual system.

\section{Implementation}

This is the application of the information generated from the Operations Research model. After careful interpretation of the results and the final solution approved by the decision maker, it is then implemented or incorporated into the organization. It is the effectiveness of Operations Research in solving the problem it is expected to solve that determines its integration into the organization. Sometimes, the solution may not be implemented because although technically valid, management may consider that it should not be implemented. In implementing the results of Operations Research, managers must consider both qualitative and quantitative factors as stated earlier. That is why Lucey (2002) pointed out that Operations Research is an aid to the decision-making process. In otherwords, the results of Operations Research should be combined with qualitative information in making decisions. The Operations Research techniques provide information that can aid the manager in making effective decisions. Hence, in making the ultimate decision, the manager must combine the information obtained with his/her expertise and experience.

The model's results and the decisions based on the results provide feedback to the original model. The original problem can then be modified to test different conditions and decisions the manager thinks might occur in the future. As such, the Operations Research process is continuous rather than simply providing one solution to one problem hence the feedback loop. The experiences gained from implementation provide feedback to different stages in the Operations Research modelling process.

\section{Review and Maintain}

After implementation, the performance of the model should be carefully and constantly monitored to ensure that it actually does work and fulfill its objectives. The review process should be at regular intervals so that appropriate adjustments can be made to meet changes in conditions which can render the implemented solution inappropriate (Lucey, 2002). All organizations are subject to change. Consequently, no solution remains optimal forever. Changes in the system or in the environment of the system make it essential to continually review the models used and the existing solutions to see if adjustments are required. Adjustments should be updated dynamically to ensure that the recommendations are enabling the organization to meet its objectives.

\section{The Techniques of Operations Research}

This section discusses the various techniques of Operations Research that can be used by managers of Nigerian business organizations. This will provide a broad description of Operations Research techniques and what they can be used for. To achieve this, we classify Operations Research techniques into five categories as shown below:

\section{Linear Mathematical Programming Techniques:}

- Linear Programming 
- Transportation

- Assignment

- Integer Programming

- Goal Programming

Probabilistic Techniques:

- Decision Analysis

- Game Theory

- Markov Analysis

- Queuing

- Simulation

- Forecasting.

Inventory Techniques:

- Inventory Models

Network Techniques:

- $\quad$ Network Models (CPM/PERT)

Non-linear Programming:

- Dynamic Programming

- Non-Linear Programming.

\section{Linear Programming}

According to Taha (2002) Linear programming is a technique for resolving problems of resource allocation. It is designed to assist management in its optimization decisions involving the use of competing resources. It offers a simplified technique for specifying how to use limited resources or capacities of a business to obtain a particular objective such as least cost, least time or highest margin when these resources have alternative uses. There are situations where a business organization is faced with the problem of allocating its resources which include money, materials, land, machine time and labour time. It helps in the process of selecting the most desirable course of action from a number of available courses of action thereby giving management information for making effective decisions about the resources under its control. Its applicability is however restricted to problems that are entirely linear. The general formulation of a linear programming problem is given as:

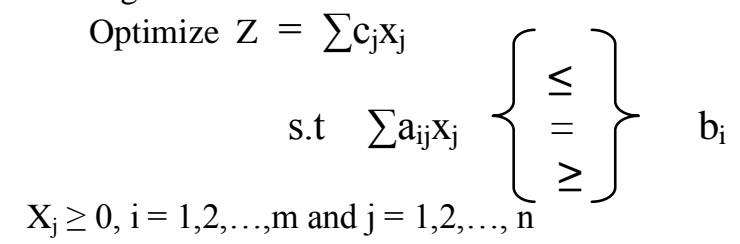

Where:

$\mathrm{x}_{\mathrm{j}}=$ Decision variables

$\mathrm{c}_{\mathrm{j}}=$ Coefficients in the objective function

$\mathrm{Z}=$ The objective to be optimized (either maximization or minimization)

$b_{i}=$ The set of constraints

$\mathrm{a}_{\mathrm{ij}}=$ The coefficients of the decision variables

Linear programming problems can be solved using the graphical method, the matrix method or the simplex method (Spyros, 1999). Linear programming technique has certain distinct advantages such as:

- It offers insight and perspective into the problem at hand, calling forth logical organization of information in the manner that scientific approach to a problem would require.

- It gives the decision maker an opportunity to take into account all possible solutions to the problem.

- It enables the decision maker to consider a true reflection of his limitations and constraints impinging upon his operations.

- Given the dynamic nature of the environment, linear programming technique offers the type of flexibility management might require to cope with changing conditions. Results obtained through linear programming can be easily re-evaluated for changing conditions through sensitivity analysis (Ekanem and Iyoha, 2002).

\section{Transportation Model}

An important factor in logistics management is the determination of the lowest cost transportation provider from among several alternatives. In many cases, it is possible to transport items from a plant or 
warehouse to a retail outlet or distributor. The major modes of transportation in Nigeria include road, rail, air, water and pipeline. Factors to consider when making a decision include comparative cost of alternative modes, kind of product and transportation time. A quantitative technique that is used for determining the least cost means of transporting products is the transportation model. It helps to determine the quantity of the item to be transported to each destination on a periodic basis in order to minimize the total cost of transportation or to maximize revenue (Levin et al, 1992). Apart from transportation problem, the transportation model can be used for machine assignment, plant location and product mix problems (Gupta and Hira, 2004).

There are several methods for solving transportation models. An initial solution can be found using Northwest-corner Rule, Least Cost Method or Vogel's Approximation Method while optimal solution can be obtained using Stepping-stone Method or the Modified Distribution Method (Taylor and Bernard, 1996).

\section{Assignment Model}

The assignment model is a special form of a linear mathematical programming model that is similar to the transportation model. However, in the assignment model, the supply at each source and the demand at each destination are each limited to one unit (Agbadudu, 1996). Assignment problems can be solved using Hungarian method, which involves rapidly reducing the original matrix and finding a set of $\mathrm{n}$ independent zeros, one in each row and column, which gives an optimal solution. This technique can be used to assign salespeople to different territories to maximize sales and profits.

\section{Integer Programming}

An integer programming model is a model that has an algebraic representation that is identical to a linear programming model with the exception that one or more of the structural variables is required to have only integer value (Ekoko, 1999). In linear programming, the solution of the variables need not necessarily be a whole number. However, there are situations when it becomes imperative that the solution must be a whole number. There are some situations in business that require whole numbers rather than fractions. For example, a business organization can only employ say 100 or even more people but not 1003/4 people.

Integer programming models are often classified as being either mixed integer programming models or pure integer programming models. If all the variables must take only integer values, it is pure integer programming. If only some specified variables have to be integers and others may be non-integers, we have a mixed integer programming problem. Integer programming problems can be solved using Branch and Brand method or Gomory Algorithm (Ekoko, 1999).

\section{Goal Programming}

This is a type of linear mathematical programming that can be used to analyze decision situations involving multiple goals, which sometimes are complementary or conflicting. Linear programming model has only one objective function, as such, it is inappropriate for many decision making situations in which a manager is concerned with several potentially conflicting objectives. Goal programming provides a method for extending linear programming to accommodate models in which there is more than one objective. For example, there are times when management may want to maximize profits and increase wages paid to employees or to upgrade product quality and reduce product cost. Goal programming considers all the decision maker's objectives in the function to be optimized. The pervasiveness of multi-objective decisions make goal programming an important tool for managers. It requires management to set some estimated targets for each goal and assign priorities to them, that is, to rank them in order of importance. With this information, goal programming tries to minimize the deviations from the targets that were set. It can be solved using the Modified Simplex Method (Anderson et al, 1997).

\section{Decision Analysis}

Decision analysis is a systematic approach to decision making in situations where there are a number of alternative courses of action and some uncertainty as to the precise outcomes of the various possible options (Agbadudu, 1996). One of the features of problems which exist in the real-world is the existence of uncertainty, this is, at the time the decision is made, the decision maker is uncertain as to which state of nature will occur in the future and thus has no control over them. In dealing with such problems, it is essential to obtain a measure of the uncertainty. Most business decision situations can be categorized into two classes, decision-making situations where probabilities cannot be assigned to future occurrences and decision situations where probabilities can be assigned. Within this context, several decision-making criteria are available. In the case where probabilities could not be assigned to the occurrence of outcomes, the maximax, maximin, minimax regret, equal likelihood and Hurwicz decision criteria can be used. In the case where probabilities could be assigned to the states of nature of a decision situation, the expected value criteria and decision trees are used (Agbadudu, 1996). 


\section{Games Theory}

Games theory provides a framework for analyzing decision making among firms in a competitive situation. In the business world, many decisions are made in competitive situations where the decision of a competitor affects the decision of a firm. According to Camerer (2003) all situations in which at least one agent can only act to maximize his utility through anticipating (either consciously or just implicitly in his behaviour) the responses to his actions by one or more other agents is called a game. The purpose of the game is for each player to select the strategy that will result in the best possible payoff or outcome regardless of what the player's opponent does. The term player is used to denote each firm, which takes part in games related to decisionmaking. Each player in a game faces a choice among two or more possible strategies. A strategy is a predetermined programme of play that tells a firm what actions to take in response to every possible strategy its competitors might use. The best strategy for each player is known as the optimal strategy.

When each player in the game adopts a single strategy as an optimal strategy, then pure strategy game exists. On the otherhand, when the player adopts a mixture of strategies, then it is a mixed strategy game. A pure strategy game can be solved according to the minimax decision criteria while a mixed strategy game can be solved using expected gain and loss method or linear programming (Ekoko, 1999).

\section{Markov Analysis}

Markov analysis is a technique for analyzing the current behavior of some variables in an effort to predict the future behavior of that same variable. According to Taylor and Bernard (1996) a markov chain is a collection of random variables $\left(\mathrm{x}_{\mathrm{t}}\right)$ (where the index $\mathrm{t}$ runs through $0,1, \ldots$ ) having the property that given the present, the future is conditionally independent of the past. Markov chain is a sequence of events or experiments in which the probability of occurrence for an event depends on the immediately preceding event. It is also referred to as markov process. The controlling factor in a markov chain is the transition probability. It is a conditional probability for the system to go to a particular new state, given the current state of the system. Thus, markov analysis is specifically applicable to systems that exhibit probabilistic movement from one state or condition of the system to another overtime. It has been successfully applied to a wide variety of decision situations such as examining and predicting the behavior of consumers in terms of their brand loyalty and their switching from one brand to another, assessing the behavior of prices, manpower planning, estimating bad debts or credit management and maintenance planning.

\section{Queuing Model}

Queuing models are techniques for analyzing problems concerned with providing service to customers in a line. All queuing situations involve the arrival of customers at a service facility where some time is spent waiting for and receiving the desired service. The customers could be persons or objects like unfinished items proceeding to the next stage of production (Agbadudu, 1996). Given a model of a queuing system, some of the descriptions of the system that can be obtained from the model are as follows:

- The relative frequency or probability that the system will be idle.

- The probability that there will be $\mathrm{n}$ customers waiting in the queue.

- The expected number of customers waiting in the queue.

- The probability that it will take more than $t$ units of time to service a customer.

- The average time a customer spends in the queue waiting for service.

- The average time required to get through the entire system.

The description above can be invaluable in business decision making. Queuing can be used for solving problems such as the determination of the optimum number of servers, repairs and maintenance of equipment subject to breakdown and outsourcing decisions. A cost is usually associated with waiting because it involves consumption of time. Long queues may cause customer annoyance and perhaps a switch to another firm. However, if there are too many service points, they may often be idle and also involve high cost to the organization. The objective of queuing models is to strike an optimal balance in minimizing waiting costs to both the customer and the service facility.

\section{Simulation}

Simulation is a quantitative technique for evaluating alternative courses of action through experimentation performed via a mathematical model in order to represent actual decision making under conditions of uncertainty (Agbadudu, 1996). It involves the operation of a model or simulator, which is a representation of the system. The model is amenable to manipulation, which would be impossible, too expensive or impractical to perform on the entity it portrays. The operation of the model can be studied and the properties concerning the behaviour of the actual system or its sub-system can be inferred. 
At times, there are problems which cannot be resolved analytically because the problem involves a large number of interacting factors which will lead to considerable complications when analytical techniques are applied. Also, in situations where certain assumptions will make the suggested optimal solution not to be accurate, simulation would be the appropriate method for tackling such problems. It can be applied to decisions regarding manufacturing of alternative kinds of products, choosing location of a plant, selecting suitable processes of production or arranging for the sales of the finished product. .In all these situations, management must examine and weigh alternatives. When alternatives are few in number and management has experience, decisions may be simple. However, when he has little experience, lacks information or has a problem not amenable to simple numerical analysis or trial and error methods, actual experimentation may be too expensive and time consuming, simulation procedures may then be extremely helpful.

\section{Forecasting}

A forecast is a prediction of what will occur in the future (Barry and Stair, 1997). Managers are constantly trying to predict the future regarding a number of factors in order to make decisions in the present that will assure the continued success of their firms. Often, a manager will use judgement, opinion or past experience to forecast what will occur in the future. However, a number of mathematical methods are also available to aid the manager in making such decisions. Forecasting is the process of developing assumptions or premises about the future that managers can use in planning or decision-making. There are a variety of forecasting methods, the applicability of which are dependent on the time frame of the forecast, the existence of patterns in the forecast and the number of variables the forecast is related to. Basically, these methods include moving averages, exponential smoothing, the decomposition of seasonal data and regression analysis (Levin et al, 1992).

\section{Inventory Models}

The term inventory is used to denote the quantity of goods or materials kept on hand for future use in production or sales (Kalavathy, 2002). By carrying large inventories, one can minimize the chances of shortage or make more profit in case of a price rise or enjoy economics of scale due to purchasing in bulk. However, large inventories require more carrying costs in terms of insurance charges, taxes, storage, obsolescence and deterioration. Inventory models help to strike a balance between having too many quantities of an item on hand and running out of stock. It deals with the following decisions:

- What is the best quantity of an item to order each time an order is placed?

- When should order be placed?

- What quantity of the item should be held as safety stock?

- Should management take advantage of discount offer?

The basic inventory model is the Economic Order Quantity (EOQ) Model. It helps in identifying the order quantity that can minimize the total cost of carrying inventory. It is given as:

Where:

$$
Q=\sqrt{\frac{2 \mathrm{CoD}}{\mathrm{C}_{\mathrm{h}}}}
$$

$$
\begin{aligned}
& \mathrm{Q}=\text { Economic Order Quantity } \\
& \mathrm{Co}=\text { Ordering Cost } \\
& \mathrm{D}=\text { Annual Demand } \\
& \mathrm{C}_{\mathrm{h}}=\text { Holding Cost }
\end{aligned}
$$

The EOQ model is more appropriate for a purchasing situation. In a situation where the firm produces the items, the model becomes:

EPQ $=\sqrt{\frac{2 \mathrm{CoD}}{\mathrm{C}_{\mathrm{h}(1-\mathrm{d} / \mathrm{p})}}}$
Where:
$\mathrm{EPQ}=$ Economic Production Quantity
$\mathrm{Co}=$ Set-up cost
$\mathrm{C}_{\mathrm{h}}=$ Holding cost
$\mathrm{D}=$ Annual demand
$\mathrm{d}=$ Periodic demand rate (that is, daily, weekly, fortnightly or monthly)
$\mathrm{p} \quad=$ Periodic production rate (also, daily, weekly, fortnightly or monthly)

\section{Network Models}


In many business situations, there are a number of different activities which must be performed in a specific sequence in order to accomplish a project. Some of these activities can be performed simultaneously while others are done one after the other. Network models enable the manager to consider the nature of the activities that are required for the completion of a project, to define the critical path and then to make decisions consistent with his resources and requirements. It also enables management to plan ahead, to take stock of the situation at every stage of planning and may even alert him in time to obviate future sources of trouble. Thus management may be in a position to plan the best possible use of resources in a way that the milestone is reached within the appointed time and given costs.

There are two basic network models, the Critical Path Method (CPM) and Programme Evaluation and Review Technique (PERT). CPM is used for scheduling and controlling projects where the time needed to complete each of the scheduled activities is known. It assumes that the duration of each activity is known with certainty but PERT assumes that each activity occurs with probability (Hira, 1990). Hence, it is capable of dealing with in-built uncertainties. This is achieved by using three time estimates, optimistic, most probable or normal and pessimistic. The average of these three time estimates is usually used for analysis. The main objectives of these techniques are to minimize total completion time, costs involved and idle resources. These techniques have been applied to many management and allocation problems such as planning, scheduling and evaluation of projects.

\section{Dynamic Programming}

Dynamic programming is a technique which is useful when a decision maker is faced with a multistage decision. It is often concerned with the allocation of scarce resources. The states at a stage are often the different resource levels available at that stage. Given each state, a number of decisions are possible, each of which results in a return. For each state, the best decision is determined as the one that results in the greatest return. These states and decisions are then related to the next stage in the solution process with a transition function. This means that the solution approach of dynamic programming is to breakdown a problem into smaller sub problems called stages and then solves these stages sequentially. The outcome of a decision at one stage will affect the decision made at the next stage in the sequence. For example, when a manager specifies a production level for his assembly line at the start of each month, the choice of a production level for the nth month can be influenced by and in turn can influence production levels selected for prior and subsequent months. The principle behind dynamic programming is known as the principle of optimality. It states that "an optimal policy has the property that whatever the initial state and initial policy are, the remaining decisions must constitute an optimal policy with regard to the state resulting from the first decision" (Gupta and Hira, 2004).

Dynamic programming is a unique approach to problem solving. It uses other techniques within its overall solution approach. As such, it is applicable to a wide variety of problems. It has been successfully applied to such areas as equipment replacement, production scheduling, inventory management, and for planning advertising expenditures. As a result of its wide application, there is no single algorithm that can be used to solve all problems and so a separate algorithm is normally developed for each problem.

\section{Non-linear Programming}

Non-linear programming is a mathematical technique for analyzing problems in which the objective function and constraints are not linear. The solution approach for problems with non-linear relationships requires the application of substitution method which is used for models that contain only equality constraints and calculus.

A number of studies have examined the extent of use of these techniques in business organizations in several countries. Turban (1972) examined Operations Research activities at the corporate level in business organizations. The results indicated how widely the techniques had been applied to current projects in the United States of America and that simulation and linear programming were the most widely used techniques. Cook and Russel (1977) reported that in 1974, they did a study to examine the Operation Research techniques that are used by companies in the United States of America. They found that linear programming, inventory control models and PERT/CPM were mostly used. Ledbetter and Cox (1977) studied companies in Britain and got similar results that simulation and linear programming were the most frequently used techniques. Schweigman (1979) studied Tanzanian companies and Wright (1981) studied companies in Ghana and got similar results. Lane et al (1993) investigated the techniques that practitioners and educators have found to be most important and most useful. The study was based on questionnaires and they found that the techniques that are used in order of importance are statistical methods, linear programming, simulation, network models, decision analysis, waiting line models, inventory models and dynamic programming. Morgan (1999) studied 12 companies and 3 practitioners. The results gave further support to linear programming, simulation and network 
models as being the most frequently used Operations Research techniques. He concluded that the barriers to the use of Operations Research can best be removed by increasing managers' understanding of the techniques.

In Nigeria, several researchers have recommended one Operations Research technique or the other to companies for efficiency and effective decision making. Unyimadu (1993) did a study on how games theory can be applied to the functional management strategies of firms in the banking industry. He recommended that games theory should be adopted for monitoring competition in the banking industry in Nigeria. Alimhinaga (2000) applied markov chain on data from Guinness Nigeria Plc in order to determine the brand loyalty of consumers to its products. The study revealed that there was a dwindling trend in the brand loyalty of consumers to Guinness. He therefore recommended that firms in the brewery sector should apply markov chain model in analyzing brand switching pattern and market shares of brands at regular intervals for better marketing decisions and policy formulation to obtain repeat purchase of their products. In addition, Ighomereho (2007) conducted a study to determine the extent to which Nigerian quoted companies actually use these techniques and it was found that managers in Nigerian business organizations use the techniques but the extent of use is small. This finding is not surprising as Nigeria is a developing country that is still growing in terms of technology and computer application. Development in computer technology has made it possible for Operations Research techniques to be easy to use. Computations in many Operations Research techniques are usually too large to carry out manually because they require large amount of data and many decision variables. Currently, there are softwares that make the computation to be very easy and also allow the decision maker to combine the results with executive judgement and experience to make better decisions. The low level of use can also be attributed to the few experts in Operations Research that we have in Nigeria. With respect to the most frequently used techniques, it was found that managers in Nigeria use forecasting techniques, network models, inventory models, simulation, linear programming, goal programming, games theory, decision analysis, markov analysis, queuing models and transportation model. The techniques that they do not use include assignment model, integer programming, dynamic programming and nonlinear programming. This finding is similar to that of Lane et al (1993) except for dynamic programming. It however contradicted the findings of Schweigman (1979) and Wright (1981) that the most commonly used technique in developing countries is linear programming. This study revealed that the most commonly used technique is forecasting techniques. This may be as a result of increased uncertainty and complexity of the Nigerian business environment.

\section{Areas of Application of Operations Research in Business Organizations}

Operations Research as a problem solving and decision-making science can be applied to a variety of issues in business organizations. Levin et al (1992) and Gupta and Hira (2004) classified the application of Operations Research in organizations based on the functions of management. Based on this foundation, this paper outlines the various areas of activities where Operations Research can be applied in Nigerian business organizations.

\section{Production/Operations}

- Location and design of production plants.

- Balancing plant capacity with market requirements.

- Mixing chemical ingredients to achieve least cost.

- Preparation of forecasts for various inventory items.

- Project scheduling and sequencing.

- Determination of the number of items to be produced.

- Deciding whether to manufacture or to purchase components.

- Making quality control more effective.

- Maintenance policy.

\section{Finance/Accounting}

- Forecasting capital requirement and cash-flow

- Allocating capital among various alternatives

- Building cash management models

- Managing an investment portfolio

- Profit planning

- Deciding on the most effective dividend policy

- Assigning audit teams effectively

\section{Marketing}

- The allocation of promotion budget to advertising, personal selling and sales promotion.

- Effectively allocating advertising among various media (print, broadcast and internet). 
- Location of warehouses and distribution centres to minimize distribution cost.

- Determining the best product mix.

- Assigning salespeople to territories to maximize sales effectiveness.

- Predicting customer loyalty in future periods.

- How and when to purchase at the minimum procurement cost.

- Consumer preferences in terms of product attributes.

- How to be proactive and reactive to competitive strategies.

\section{Human Resources}

- Scheduling training programmes to maximize skill development and retention.

- Selection of personnel.

- Assignment of jobs to personnel.

\section{Conclusion and Recommendations}

From the above areas of application, it can be concluded that the techniques of Operations Research are useful tools for decision making in business. Although, the techniques are tools for decision making and not the complete decision making process, its role and usefulness in decision making cannot be overemphasized. The problems faced by different categories of managers in today's contemporary world are mind-boggling in scope. It is no longer possible to depend solely on subjective decision making. Therefore, Operations Research techniques should be taken as an aid to decision making and a supplement to judgement, experience and intuition. It is therefore recommended that:

- When teaching Operations Research in higher institutions in Nigeria, case studies should be introduced. Real life problems should be solved in the classroom so that students can begin to see it as a problem solving tool rather than a compulsory course that must be passed.

- Operations research is a practical decision making tool. It is not abstract in nature because the issues it addresses are things we experience on a daily basis. So when teaching Operations Research, it should be demystified.

- The use of computer and Operations Research software should also be introduced. This is very important because the extent of use cannot really increase without the use of computer. All the techniques discussed in the literature review can be solved using computer. With the software, the manager need not bother to solve the mathematics involved. All that is required is to input the data and the computer will bring out the result.

- The Institute for Operations Research of Nigeria (INFORN) should be more functional and vocal in sensitizing managers of business organizations to apply the techniques in their operations. This could be achieved through regular workshops, training, seminars and conferences. They should also market these programmes and encourage managers of business organizations to attend.

- The Institute for Operations Research of Nigeria (INFORN) should also be visible and accessible to students especially at the undergraduate level. They should be encouraged to be members of the institute.

- Other professional bodies in management such as the National Institute of Marketing of Nigeria (NIMN), Nigerian Institute of Management (NIM) and Chartered Institute of Personnel Management (CIPM) should incorporate Operations Research in their executive training programmes and workshops.

\section{References}

[1] Agbadudu, A.B. (1996). Elementary Operations Research, Benin City: A.B. Mudiaga.

[2] Agbadudu, A.B. (2006). Operations Research, Mathematics and Social Sciences: The Link, Inaugural Lecture Series 86 of the University of Benin, Uniben Press.

[3] Akingbade, F., Luck, M. and Patal, N. (1991). Concepts and Applications of Operational Research in Development Management, Lagos: Centre for Management Development.

[4] Alimhinaga, J.I. (2000). How a Firm can Strive for Higher Repeat Purchasing Rates of Its Products: A case Study of Guinness Nigeria PLC, Unpublished MBA Project, University of Benin, Benin City.

[5] Anderson, D.R, Sweeney, D.J. and Williams, T.A. (1997). An Introduction to Management Sciences, New York: West Publishing Company.

[6] Barry, R. and Stair, R.M. (1997). Quantitative Analysis for Management, New York: Prentice Hall, Inc.

[7] Camerer, C. (2003). Behavioural Games Theory; Experiments in Strategic Interaction, Princeton: Princeton University Press.

[8] Churchman, C.W. and Arnoff, E.L. (1957). Introduction to Operations Research, New York: John Wiley \& Sons, Inc.

[9] Cook , T.A. and Russel, R.A. (1977). Introduction to Management Science, New Jersey: Prentice - Hall.

[10] Ekanem, O.T. and Iyoha, M.A. (2002). Managerial Economics, Benin City: March Publishers.

[11] Ekoko, P.O. (1999). Basic Operations Research in Science and Social Science, Benin City: United City Press.

[12] Foster, F.G. (1986). Experiences with Developing Management Sciences/Operational Research in Nigeria, Operations Research. Vol.37, No. 2, 217-221.

[13] Griffen, R.W. (1987). Management, Boston: Houghton Mifflin Company.

[14] Gupta, P.K. and Hira, D.S. (2004). Operations Research, New Delhi; S. Chand \& Company Ltd.

[15] Hira, D.S. (1990). Project Management with PERT AND CPM, New Delhi: S.K. Kataria \& Sons. 
[16] Ighomereho, O.S. (2007). The Utilization and Integration of Operations Research Techniques in Nigerian Business Organizations, Unpublished M.Sc Project, University of Benin, Benin-City.

[17] INFORMS, (2005). Operational Research: The Secret of Better Decision Making in a Complex World, Retrieved February 16, 2006 from http/www.A:/What\%20is\%20OR-MS. Htm.

[18] Kalavathy, S. (2002). Operations Research, New Delhi:Vikas Publishing House PVT.

[19] Lane, M.S., Mansour, A.H. and Harpell, J.L. (1993). Operations Research Techniques, Interfaces, Vol 23,63-68.

[20] Ledbetter, W.N. and Cox, J.F. (1977). Are OR Techniques Being Used. Industrial Engineering, February: 19-21.

[21] Levin, R.I., Rubin, D.S., Stinson, J.P. and Gardner, F.S (1992). Quantitative Approaches to Management, New York: McGrawHill, International.

[22] Lucey, T. (2002). Quantitative Techniques. London: Thompson Learning.

[23] Magee, J.F. (1973). Progress in the Management Sciences, TIMS, Interfaces, Vol. 3 February, 59-61.

[24] Morgan, C.L. (1999). A Survey of Management Sciences/Operations Research Surveys, Interfaces, Vol. 19, November December, 20-23

[25] Nickels, W.G., McHuhg, J.M. and McHugh, S.N. (2002).Understanding Business, New York: McGraw-Hill

[26] Saaty, T.L. (1961). Elements of Queuing Theory, New York: McGraw-Hill Book Company.

[27] Schweigmen, C. (1979). Doing Mathematics in a Developing Country, Linear Program with Application in Tanzani, Journal of Operations Research Society. Vol. 30

[28] Simon, H. (1997). Administrative Behavior: A Study of Decision-Making Processes in Administrative Organizations, New York: The Free Press.

[29] Spyros, R. (1999). An Introduction to Linear Programming and the Simplex Algorithm, Retrieved January 12, 2006 from: http://www.amazon.com.

[30] Taha, H.A. (2002). Operations Research: An Introduction. Singapore: Pearson Education Inc.

[31] Taylor, B.W. and Bernand, W.T. (1996). Introduction to Management Science. New Jersey: Prentice Hall.

[32] Turban, E. (1972). A Sample Survey of OR Activities at the Corporate Level, Operations Research, Vol. 20, No. 3, 181-185.

[33] Unyimadu, S.O. (1993). Application of Game Theory to the Functional Management Strategies in the Commercial Banking Industry in Nigeria, Unpublished Ph.D. Thesis, University of Benin, Benin City.

[34] Wayne, L.W. (1994). Operations Research: Applications and Algorithms, Belmont California:Wadsworth Publishing Company.

[35] Weihrich, H. and Koontz, H. (2005). Management: A Global Perspective, New Delhi: McGraw-Hill Publishing Company Ltd.

[36] Wright, D.J. and Kemball, C.D. (1981). The Search for Appropriate OR: A Review of OR in Developing Countries, Journal of Operations Research Society, Vol.32, 47-52. 